\title{
Coaching Today's Auditors: When Do Workpaper Reviewers Professionally Develop Their Preparers?
}

\begin{abstract}
Audit workpaper review is a quality control mechanism intended to detect preparer errors in the short-term and professionally develop preparers in the long-term. Currently, it is unclear as to what factors drive reviewers to professionally develop (or not develop) their preparers. Furthermore, whether error detection and professional development complement or compete during supervisory review is not known. As audit teams become more global, new contextual factors are introduced into the audit environment that may influence a supervisor's review quality. In this study, we investigate how the preparer's office location (local vs. international) and the likelihood of preparer recurrence affect the reviewer's propensity to focus on the professional development of the preparer. We find that reviewers identify more with preparers from their local (vs. international) office and, as a result, focus more on professionally developing local preparers. We also observe that, regardless of office affiliation, reviewers are more apt to coach preparers who are likely (vs. unlikely) to recur the next year because they anticipate reaping future personal benefits from recurring preparers. Finally, we find that reviewers who focus more on developing preparers are also more likely to detect errors in preparer audit documentation.
\end{abstract}

Keywords: global audit teams, international office, professional development, recur, review quality, workpaper review

Data Availability: Contact the authors. 


\section{Introduction}

Workpaper review is a quality control mechanism that serves two main objectives: to ensure audit quality on the engagement by detecting workpaper preparer errors and to professionally develop the preparer (Lambert and Agoglia [2011], Trotman, Bauer, and Humphreys [2015], Andiola and Bedard [2018]). Professional development involves improving employees’ job performances and enhancing their capabilities by providing feedback, encouraging critical thinking, and stimulating future learning (Heslin, Vandewalle, and Latham [2006]; Gregory and Levy [2010]). Detecting errors during the review process is fundamental to ensuring audit quality in the short-term, but how the review process professionally develops preparers carries longer-term benefits (Westermann, Bedard and Earley [2015]). It is analogous to giving a man a fish (reviewer detecting/correcting errors) versus teaching a man to fish (developing preparers’ abilities).

Extant audit research primarily focuses on a reviewer's ability to detect errors during the review process (e.g., Tan and Trotman [2003], Agoglia, Hatfield, and Brazel [2009], Frank and Hoffman [2015]), while very few consider the coaching provided by the reviewer (e.g., Wilks [2002], Peecher, Piercey, Rich, and Tubbs [2010]). ${ }^{1}$ Currently, it is unclear as to what factors drive reviewers to professionally develop (or not develop) their preparers. In addition, whether error detection and professional development complement or compete during supervisory review is an open question. As audit teams become more global, new contextual factors are introduced into the audit environment that may influence a supervisor's review quality. Therefore, the main objectives of this study are to: (1) examine if and how two key contextual factors, namely the office of the preparer and the likelihood the preparer will recur on the engagement, affect

\footnotetext{
${ }^{1}$ Actions taken to foster professional development are often referred to as"coaching"in practice.
} 
whether the reviewer professionally develops the preparer, and (2) determine whether the error detection and professional development aspects of the review process complement or compete with one another.

Understanding the ability of the review process to function as a professional development mechanism is becoming increasingly important as audit teams become more global (Carson [2014], Downey and Bedard [2018]). Approximately 80 percent of Fortune 500 company audits involve international auditors engaged by the lead U.S. audit team, and more than half of public company audits performed by global network firms include the work of other auditors in international offices (PCAOB [2016]). As a result, changes are occurring in practice that are requiring lead engagement teams in the U.S. to review workpapers prepared by international auditors (IAASB [2013a], BDO [2016], Sunderland and Trompeter [2017]).

PCAOB inspection results, enforcement actions, and standard setting initiatives highlight an array of concerns about work performed by international auditors, particularly on group audits (PCAOB [2014], [2016], [2017a]). ${ }^{2}$ As such, regulatory efforts around supervision and audit quality for global teams are pressuring the auditors supervising these engagements to either develop the professional skills of international preparers (e.g., through the workpaper review process) or identify another staffing solution (e.g., have U.S. auditors complete the work or assign a U.S. expatriate to the international office, see Downey and Bedard [2018]). However, in most countries audit professionals must be locally licensed to perform work (Carson [2009],

\footnotetext{
${ }^{2}$ Group audits are characterized in the following quote: “A growing number of audits, particularly audits of global enterprises, are being conducted by more than one firm, legally distinct from one another, but commonly affiliated in a global network. The use by the lead auditor of such other auditors in an audit, often located in a different country, and at times in several different countries, can provide a number of benefits...” (Ferguson [2016]). Former PCAOB board member and IFIAR chairman Ferguson [2016] further states that: "The use of other auditors in a multinational environment, however, also introduces a number of challenges that can lead to inadequate audit performance...The International Forum of Independent Audit Regulators' annual survey of inspection findings, including findings from more than thirty audit regulators around the world, has identified, for a number of years, supervision of group audits as a frequent area of inspection findings in the audits of public interest entities.”
} 
NASBA [2018]), and prior research finds mixed evidence on the effectiveness of expatriates (e.g., Bonache, Langinier, and Zarraga-Oberty [2016]). Thus, the most compelling option for U.S.-based supervisors is to focus on professionally developing international preparers, who are performing an increasingly large volume of work on U.S.-led audits (PCAOB [2016]).

Still, these supervisors may not be as inclined to coach or develop international preparers as those based in their local office. Social Identity Theory (SIT) suggests that reviewers' perceptions of commonalities or differences between themselves and a preparer are likely to manifest as identifying more with preparers from their local office and less with international preparers (Tajfel [1981]). In turn, the level of identification may influence the extent to which the reviewer is willing to professionally develop the preparer (e.g., Dovidio, Kawakami, Johnson, Johnson, and Howard [1997]). We therefore investigate how the preparer's office location (local vs. international) affects reviewers' identification with the preparer, and in turn, their propensity to focus on the professional development of the preparer.

The location of a preparer's office is a fixed environmental factor that largely cannot be controlled by either the preparer or the reviewer. In contrast, preparer recurrence on the engagement is a more controllable factor because the firm, the preparer, and/or the reviewer may be able to influence the likelihood that a preparer returns to the engagement the following year. From a practical perspective, recurrence is beneficial for the audit team as it provides efficiency gains with team members possessing client-specific knowledge developed in prior years (Christensen and Newton [2017]). However, Christensen and Newton [2017] report that turnover on engagement teams is common, and not all engagement turnover is due to employees leaving the firm. For example, preparers may prefer to pursue another industry or not feel a fit with the supervisor’s leadership style (e.g., Church [2014]). Therefore, during an engagement, preparers 
may indicate their desire to recur (or not recur) to their supervisor on the engagement team. If reviewers anticipate working with a preparer again on the next year's engagement, reviewers likely have a greater personal incentive to invest in professionally developing the preparer now as such efforts may provide personal benefits to them next year. As such, we examine whether the likelihood of preparer recurrence influences reviewers' willingness to coach preparers. We also consider whether an emphasis on professional development either enhances or detracts from the other objective of the review process: error detection.

To test our hypotheses, we conducted an experiment where 132 practicing audit seniors completed a workpaper review of a preparer's search for unrecorded liabilities. We manipulated the preparer's office location (local or international) and the likelihood of preparer recurrence (likely or unlikely) in a 2x2 between-participants design. Participants received information on the engagement and the preparer, followed by the preparer's workpaper and applicable supporting evidence. While performing their review, participants could leave review comments for the preparer and make changes to the workpaper. Following the task, participants completed debriefing questions, including those designed to measure their identification with the preparer and their anticipation of future personal benefits from coaching the preparer. Our dependent variables measured both dimensions of review quality: the extent to which the review comments focused on professionally developing the preparer and the number of seeded errors identified by reviewers.

Consistent with our predictions, results indicate that reviewers identify more with preparers from their local (vs. international) office and focus more on professionally developing the preparers with whom they identify (e.g., offering probing questions vs. simply requesting corrections). In addition, when preparers are likely (vs. unlikely) to recur on the engagement, 
reviewers anticipate a personal benefit to coaching these preparers. In turn, reviewers are more apt to provide review comments that develop recurring preparers. An important implication of these findings is that, despite regulator concerns (PCAOB [2014], [2016], [2017a]), international preparers are unlikely to receive the intended long-term benefits of the review process. However, regardless of office affiliation, reviewers provide higher quality coaching if they expect a preparer to recur. We also find that the objectives of the review process are complementary. Reviewers who focus more on coaching the preparer also identify a greater number of seeded errors in the workpapers. Supplemental analyses reveal that the general and task-specific experiences of reviewers are associated with error detection, but do not impact review coaching. Although we observe that reviewers who focus on professional development take more time to conduct their reviews, the dual benefits of increased error detection and development of preparers likely outweigh this short-term cost.

This study contributes to both the review process literature and research on auditing in a global environment, answering several calls for research in these areas (e.g., Trotman et al. [2015]), while also informing audit standard setting and practice. First, extant research primarily considers the error detection function of the review process. Our study is the first to simultaneously examine the dual role the review process serves: error detection and professional development. Importantly, our results highlight the influence one role has on the other, as professionally developing preparers positively impacts reviewers’ error detection. This finding provides evidence of a considerably different benefit to coaching than documented in prior research (e.g., preparer learning: Vera-Munoz, Ho, and Chow [2006]; Westermann et al. [2015]). Second, despite the prevalence of international staff auditors on U.S.-led audits, this study is the first to consider the effects of the preparer's office location on the quality of the 
review process. Given the extensive turnover occurring on engagement teams (Christensen and Newton [2017]), we are also the first to examine the influence preparer recurrence may have on the review process (which is applicable to all preparers, regardless of office affiliation). While our findings raise concerns about the impact of globally-sourced audit teams on short- and longterm audit quality, they also highlight opportunities for preserving overall review quality. Specifically, when reviewers expect benefits from coaching the preparer, they develop this individual more and detect more errors. Still, Christensen and Newton [2017] report that approximately half of the hours charged by audit team members are charged by members who were not assigned to the engagement in the prior year (i.e., did not recur). Accordingly, to the extent that the human resource departments of audit firms can coordinate preparers and reviewers recurring on engagements (and make this explicit to both parties as early as possible), audit engagement quality should improve.

Finally, this study demonstrates the susceptibility of U.S. reviewers to within-group bias in a global audit environment. Emerging studies that examine the context of global engagements focus on the performance of preparers (e.g., Downey [2018], Lauck and Bhattacharjee [2017]) or overall engagements (e.g., Downey and Bedard [2018]). In contrast, we contribute evidence to inform discussions on the supervision and review of international auditors, a key concern of regulators and a focus of standard setting (IAASB [2013b], PCAOB [2016], [2017b]).

The remainder of this paper is organized as follows: The next section discusses the background literature and develops hypotheses. We then provide a description of the method and a presentation of the results. The final section concludes the paper. 


\section{Background on Workpaper Review and Hypothesis Development}

During financial statement audits, staff auditors prepare workpapers describing the work performed, methods used, and conclusions drawn. These workpapers are then reviewed by a supervising auditor (Gibbins and Trotman [2002], Agoglia, Kida, and Hanno [2003]). Because

workpaper review serves such an important function (detecting errors in the work performed and coaching preparers to improve future performance), audit supervisors allocate as much as 30 percent of their time to review and about 20 percent of this time is spent coaching preparers (Fargher, Mayorga, and Trotman [2005], Jenkins, Ater, Gimbar, Saucedo, and Wright [2018]). However, over the last 15 years significant changes to the audit environment have altered how reviewers conduct workpaper reviews (Brazel, Agoglia, and Hatfield [2004], Agoglia, Brazel, Hatfield, and Jackson [2010], Gimbar, Jenkins, Saucedo, and Wright [2017]).

One important change in the review setting is the increasing frequency of U.S.-based supervisors overseeing and reviewing the work of international preparers (e.g., foreign components of group audits) (PCAOB [2017b], Downey and Bedard [2018], Andiola, Downey, Spilker, and Noga [2018b]). In this study, we examine whether the preparer's office affiliation can affect the quality of workpaper review. Another important factor in the current environment that may influence review quality is the likelihood that the preparer will recur on the engagement in the following year. Although turnover in accounting firms is not a new problem, Christensen and Newton [2017] provide recent archival evidence on the extent to which recurrence occurs on engagement teams. The researchers illustrate that approximately half of the hours charged by team members are charged by members who were not assigned to the engagement in the prior year (i.e., did not recur). Figure 1 presents a theoretical model predicting how these two contextual factors, preparer office location (local or international) and preparer recurrence (likely 
or unlikely), may affect both dimensions of review quality: professional development and error detection. The theory supporting the model is discussed below.

\section{[INSERT FIGURE 1 ABOUT HERE]}

\subsection{PREPARER OFFICE LOCATION}

When considering whether reviewers are more apt to professionally develop a preparer from their local (vs. international) office, several factors would suggest that professional development should not depend on the preparer's location. First, regulators' concerns and standard setting initiatives (PCAOB [2014], [2016], [2017a]) are likely to be a motivating factor for U.S.-based supervisors to develop international preparers and enhance their engagements' audit quality. International preparers perform an increasingly large portion of the work on U.S. led audits (PCAOB [2016]), and U.S. auditors are being compelled to perform detailed reviews of this work (IAASB [2013a]; BDO [2016]). While summary correspondence with international auditors historically constituted sufficient supervision, detailed workpaper review processes are evolving through increased use of technology across the globe (Sunderland and Trompeter [2017]). The combination of regulatory scrutiny and high levels of deficiencies in the reviews of international preparers (e.g., Ferguson [2016], Harris [2016]) is likely to motivate reviewers to approach the workpaper review process similarly, irrespective of the location of the preparer.

Second, global teams are more common today than ever before. Not only are reviewers likely accustomed to supervising team members in remote offices, technological advances and standardization of firm practices may further decrease the perceived differences of international 
preparers. As such, international preparers may be viewed as typical members of the audit team, thus reducing the likelihood that reviewers treat local and international preparers differently. ${ }^{3}$ Still, a large stream of literature related to Social Identity Theory (SIT) suggests that individuals naturally classify themselves into groups based on salient differences (e.g., Tajfel [1981]). Preparers working out of an international office often differ on a number of dimensions from preparers working out of a reviewer's local office, including culture, ethnicity, nationality, and location. In addition, office locations may differ in relation to the level of authority required to make final decisions, ability to discuss issues with client management, etc. (Downey [2018]). When consistent differences exist along a number of attributes, individuals may have a natural tendency to categorize team members as their in-group or their out-group. Team members who share common attributes with the individual become the in-group, and those with greater differences are classified as the out-group (Cramton and Hinds [2005], Levina and Vaast [2008]). This leads to the expectation that due to greater perceived similarities with preparers from the local office, reviewers will identify more with local preparers, classifying them as ingroup members. In contrast, reviewers are less likely to identify with international preparers, classifying them as out-group members due to the presence of salient differences (Tajfel [1981]). Prior research in social psychology indicates that individuals are more willing to help ingroup members than out-group members in part because helping in-group members is perceived to be more advantageous (Dovidio [1984], Dovidio et al. [1997]). For example, in-group members are likely to be viewed as potential friends because interpersonal connections are more

\footnotetext{
${ }^{3}$ To illustrate, a representative from a Big Four accounting firm described to a member of the research team how all U.S. professional are automatically connected to all online global professionals when they login to the firm's network. Regardless of where the professionals are physically located, they can instant message each other and video chat. In other words, the development of technology has enabled real time, face-to-face communications for the firm's global workforce.
} 
likely (Byrne, Gouaux, Griffitt, Lamberth, Murakawa, Prasad, Prasad, and Ramirez [1971], Williamson and Clark [1992]). In contrast, out-group members are viewed more negatively (e.g., less predictable), and individuals are generally more reluctant to help out-group members due to higher perceived costs. For example, because individuals feel less responsible for the out-group, the time and effort required to help out-group members is harder to justify (Dovidio, Piliavin, Gaertner, Schroeder, and Clark [1991]).

Given the research on SIT and emerging research on global audit teams (e.g., Andiola et al. [2018b], Downey [2018]), we predict that reviewers will identify more with preparers working out of the same local office, relative to preparers working out of an international office. Because of this greater identification, reviewers will exhibit a greater intent to benefit local preparers when reviewing their work (illustrated by Links 1 and 2 in Figure 1).

H1: Reviewers will identify more with a preparer from the reviewers' local office (versus an international office) and, in turn, exhibit greater intentions for the preparer to benefit from the review process.

\subsection{PREPARER RECURRENCE}

While office location is typically not controllable by either the reviewer or the preparer, preparer recurrence on an audit engagement is a more manageable factor that may also influence review quality. From a practical perspective, recurrence at the staff auditor level is often beneficial to the audit team as it allows for efficiency gains associated with possessing clientspecific knowledge developed in prior years. As a result, human resource functions in audit firms could be proactive in promoting both the benefits of recurrence to staff auditors (who may not be aware of its importance) and coordinating schedules such that recurrence is highly likely.

However, there appears to be substantial variation in the extent to which recurrence occurs in practice (Christensen and Newton [2017]), and not all engagement turnover is due to 
employees leaving the firm. Engagement turnover may be due to circumstances outside of the preparer's control (e.g., their skillset may be needed on a different engagement, etc.). However, preparers may also have reasons to choose to not recur, including interest in pursuing another industry, wanting to gain experience with smaller or larger audit clients, not feeling a fit with the supervisor's leadership style, etc. Audit firms are increasingly trying to accommodate these requests to attract and retain millennials (Durocher, Bujaki, and Brouard [2016]).

Signaling preparer recurrence should cause reviewers to anticipate working with a preparer again in the future. Whether or not reviewers anticipate a future interaction with a preparer likely influences how they will conduct their review. According to Conservation of Resources Theory, individuals evaluate the costs and benefits of using their available resources when deciding how to use them (Hobfoll [1989], Halbesleben and Westman [2014]). The theory posits that in order to manage stress, individuals weigh their choices to assess which may result in the most future gains, or at least no future losses. Consistent with this, supervising auditors face a high level of stress and a number of pressures that force them to make choices about how to best allocate their time (Herda and Lavelle [2012], Kornberger, Justesen, Mouritsen [2011]). Consequently, how reviewers decide to cope with their stress may affect the approach they take when conducting their reviews.

In the audit review context, reviewers may consider whether there is a future benefit to professionally developing the preparer that outweighs the investment of their time. Andiola, Bedard, and Kremin [2018a] suggest that a preparer not recurring on an engagement is one factor that may inhibit audit supervisors from providing high quality coaching during an engagement, but do not specifically test this conjecture. When reviewers can anticipate a preparer's recurrence, they have an incentive to use their time to professionally develop the preparer now to 
reduce expending more time (resources) long-term. That is, there is a future personal benefit to be gained by investing time now to coach the preparer. In contrast, reviewers are likely to conserve their resources when a preparer is unlikely to recur. Such conservation efforts may be particularly likely given that reviewers are often not directly incentivized by firm management for coaching and developing staff auditors (Andiola, Bedard, and Westermann [2018c]). Indeed, Jenkins et al. [2018] provide recent evidence that staff auditors are not apt to recognize coaching as a primary goal of the review process.

Still, reviewers may choose to coach preparers regardless of the long-term costs or benefits. For example, some reviewers may be naturally inclined to want to coach and feel intrinsically rewarded by the activity (Heslin et al. [2006], Andiola et al. [2018a]). In addition, although audit firms may not directly reward good coaching, many encourage it through firm resources and may highlight its importance through social norms (Fogarty [1992], Covaleski, Dirsmith, Heian, and Sajay [1998], KPMG [2011]). Nevertheless, while personal motivation and social norms may impact some reviewers, we expect that the pressures and incentives in the audit environment (e.g., to maintain both efficiency and effectiveness) likely outweigh these factors. Therefore, we posit that if a preparer is more (less) likely to recur, reviewers will be more (less) likely to anticipate future personal benefits associated with the preparer. This anticipation of future benefits will lead reviewers to exhibit a greater intent to benefit the preparer when reviewing the preparer's work (illustrated by Links 3 and 4 in Figure 1).

H2: Reviewers will anticipate future personal benefits when the preparer is likely (vs. unlikely) to recur on the engagement and, in turn, exhibit greater intentions for the preparer to benefit from the review process. 


\subsection{REVIEW QUALITY: PREPARER PROFESSIONAL DEVELOPMENT AND REVIEWER ERROR DETECTION}

Intention is assumed to be the most immediate and important predictor of a person's behavior (Ajzen [2002], Sheeran [2002]). It is an indication of how hard people are willing to try and how much effort they are planning to exert in order to perform a given behavior (Ajzen [1991]). Collectively, the Theory of Planned Behavior (Ajzen [1991]) suggests that the stronger the intention of reviewers to make the review process beneficial to the preparer, the more likely the behavior will actually be performed. However, individuals' intentions are often not reflected in their subsequent behaviors (Pychyl [2009], Oriel, Mobbs, Evans, Hiscox, Navrady and Dalgleish [2012]), perhaps due to an inability to accurately self-assess their performance or due to self-presentation concerns that lead them to not report their intentions accurately (Fishbein and Ajzen [2010]). Therefore, it is important to directly connect reviewers' intentions to benefit preparers with their actions. Hence, we predict that a reviewer's willingness to benefit the preparer will positively impact the extent that their review comments focus more on professional development (illustrated by Link 5 in Figure 1).

H3: Reviewers will provide review comments that focus more on professionally developing the preparer when reviewers intend for the preparer to benefit from the review process.

By focusing on a preparer's professional development, a reviewer's ability to detect errors could either be hindered or improved. Research on multitasking suggests that when switching between two tasks that have different goals, performance on one of the tasks is likely to suffer (Wickens [1980], Tombu and Jolicœur [2004]). Several studies in auditing find a similar decrease in auditor performance when auditors multitask (e.g., Kim, Mayorga, and Harding [2017], Mullis and Hatfield [2018]). Therefore, if coaching and error detection are 
competing dimensions of the review, then too much focus on professionally developing the preparer may hinder the reviewer's ability to find errors in the preparer's work.

On the other hand, if these dimensions are complementary, focusing on professional development should cause reviewers to be more thoughtful during their reviews (e.g., expending more effort, examining details to elaborate more in their review comments, offering probing questions). As a result, this greater effort may increase reviewers' error detection (e.g., Asare, Haynes, and Jenkins [2007]). Given it is unclear theoretically how, if at all, coaching a preparer will influence reviewer error detection, we state our final hypothesis in the null (illustrated by Link 6 in Figure 1).

H4: The extent to which reviewers provide review comments that professionally develop the preparer will not influence the reviewers' detection of errors.

\section{Method}

\subsection{PARTICIPANTS}

The participants in our experiment were 132 audit seniors from an international accounting firm. ${ }^{4}$ We administered the experiment during a firm-sponsored training session. The participants' task was to review a staff auditor's/preparer's search for unrecorded liabilities and to provide review comments to the preparer, a task appropriate for our participants' level of experience (e.g., Tan and Trotman [2003]). On average, our participants had 33 months of audit experience, 98 percent of participants had experience reviewing workpapers, and 96 percent had experience with preparing and/or reviewing the search for unrecorded liabilities. In addition, 77 percent of participants had worked with auditors from another international office of their firm.

\footnotetext{
${ }^{4}$ Five additional participants started but did not complete the experimental instrument.
} 


\subsection{DESCRIPTION OF THE EXPERIMENTAL TASK AND DESIGN}

In order to test our hypotheses, we conducted a 2 (office: local or international) x 2 (recur: likely or unlikely) between-participants experiment. Participants were randomly assigned to one of the four experimental conditions. Our experimental materials were adapted from Westermann [2011] and Downey [2018]. The materials were pilot tested with auditors from multiple firms in order to refine the experimental instrument. ${ }^{5}$ The participants were asked to assume that they were the lead senior and primary reviewer of work related to the year-end audit of a division of Madison, Inc., a publicly traded manufacturing corporation. The participants were informed that their specific task was to review a preparer's search for unrecorded liabilities for the Construction Division of Madison and to provide review comments to the preparer. ${ }^{6}$ Next, the participants were told which office of the audit firm the preparer was from (local or international, see OFFICE below) and whether the preparer was likely or unlikely to recur on the Madison engagement in the next year (see RECUR below). The participants were then provided with the preparer's workpaper and supporting documents and began their review.

The content of the preparer's workpaper and supporting documentation was held constant between reviewers, and it included the workpaper documenting the preparer's testing, a space to input review comments, the accounts payable listing, a disbursement listing, and several related invoices. The preparer's workpaper concluded:

Based on the testing performed over cash disbursements...the accounts payable account is understated by $\$ 194,318$. This misstatement exceeds the tolerable error threshold of $\$ 150,000$ set by the engagement team and therefore was posted to the summary of unadjusted differences.

After completing their review, participants then completed a post-experimental questionnaire. 3.3 MANIPULATED VARIABLES

\footnotetext{
${ }^{5}$ We obtained Institutional Review Board (IRB) approval for this study.

${ }^{6}$ The search for unrecorded liabilities is an audit task performed by entry-level auditors to ensure that the financial statements appropriately reflect all expenses/payables (Abdolmohammadi [1999]).
} 
Our manipulated variables represent two contextual factors that may be important drivers of review quality in the current audit environment. The first manipulated variable is whether the preparer's OFFICE is local (the preparer was an experienced staff member working out of your local office) or international (the preparer was an experienced staff member working out of another international office of the firm). The instrument stated for the local [international] manipulation to "Assume that you have [have not] traveled to the Construction Division, which is [is not] in close proximity to the local office, and are [are not] working onsite with Sam.” This manipulation of location and physical proximity is consistent with the global group audit arrangements in public accounting firms, where international auditors are engaged by the lead U.S. audit team to help complete audit work. In addition, prior research emphasizes that ingroup/out-group formation, and in turn social identification, is only likely to occur when team members differ consistently across multiple attributes (e.g., physical proximity, nationality) (Lau and Murnighan [1998], Cramton and Hinds [2005], Andiola et al. [2018b]). The second manipulated variable is whether the preparer is likely to RECUR. We manipulated this variable by noting that the preparer was likely or unlikely to recur on the Madison, Inc. engagement the following year.

\subsection{MEASURED VARIABLES}

In addition to our manipulated variables, we have five measured variables. First, we measured the extent to which reviewers identified (IDENTITY) with the preparer using the Inclusion of Other in the Self Scale (Aron, Aron, and Smollan [1992]); a validated measure of

closeness and identity (Tropp and Wright [2001]) used in previous audit research studies (e.g., Bauer [2015]). The measure uses six Venn diagrams to illustrate the level of reviewer-preparer overlap and asks participants to "Select the number that most closely matches the professional 
closeness of your relationship with [the preparer].” Responses were given on a scale (which corresponded to the six Venn diagrams) ranging from 1 (Very Distant) to 7 (Very Close).

We also measured the extent that the reviewer believed they would personally benefit in the future from coaching the preparer (BENEFIT) using the following question: "How much would you (either on Madison or another engagement) benefit in the future from the coaching you provided Sam in the search for unrecorded liabilities testing?” Reviewer responses to the question were measured on a scale ranging from 0 (No Benefit) to 10 (Extensive Benefit). In addition, the reviewer's intentions to benefit the preparer (INTENTION) were captured with the following question: "How much would Sam benefit from the review process for the search for unrecorded liabilities testing?” Reviewer responses to the question were measured on a scale ranging from 0 (No Benefit) to 10 (Extensive Benefit).

To measure the extent to which the reviewer provided review comments that professionally developed the preparer (PROFDEV), two accounting doctoral candidates with significant audit experience (former manager and senior manager at Big Four accounting firms, respectively) were asked to go through the preparer's workpaper and then read the review comments provided by each participant. For each participant/reviewer, the independent raters were told to do the following: "After reading the review comments for each participant, please rate the amount of effort the reviewer (participant) put into [the preparer's] professional development, as evidenced by the review comments.” The raters responded on a scale ranging from 1 (Very Low Effort) to 10 (Very High Effort). The measure of PROFDEV for each reviewer is the average of the two ratings of the independent raters. ${ }^{7}$ The Appendix provides each coder's reflection on what professional development/coaching is, examples of professional

\footnotetext{
${ }^{7}$ There was a high level of correlation between the two independent raters' ratings (correlation $=0.82, \mathrm{p}<.01$ ) with a Cronbach's Alpha of 0.89 .
} 
development provided to coders prior to them conducting their ratings, and examples of review comments rated high and low for PROFDEV.

Last, the experimental materials contained three seeded errors in the preparer's workpaper. Specifically, the errors were: (1) the switching of invoice details between sample selections, (2) the failure to note that an expense should have been allocated over two periods, and (3) the failure to include a cash disbursement in the sample that was above the stated threshold for testing. The extent of reviewer error detection (ERRORDETECTION) was measured as the number of errors (0 to 3) identified by the participant in their review notes.

\section{Results}

\subsection{MANIPULATION CHECKS}

The experimental materials included two manipulation checks. For OFFICE, participants were asked which best describes the preparer: "[The preparer] works out of your local office” or “[The preparer] works at another international office of the firm.” Of the 132 participants, 117 (88.64 percent) correctly identified the office of the preparer. For RECUR, participants were asked to indicate, based on the case information, whether: "[The preparer] is likely to recur on the Madison, Inc. engagement” or "[The preparer] is unlikely to recur on the Madison, Inc. engagement.” 120 of the 132 participants (90.91 percent) correctly answered the likelihood of the preparer recurring. Overall, this suggests participants attended to the materials and the experimental manipulations were successful. All participants are included in the analyses below. ${ }^{8}$

\subsection{DESCRIPTIVE STATISTICS}

\footnotetext{
${ }^{8}$ Our results do not change if participants who failed either manipulation check are excluded from the analyses.
} 
Table 1 Panels A and B presents descriptive statistics and a correlation matrix for the factors in our model (see Figure 1 for the theoretical model). Panel A shows that, consistent with the prediction for Link 1 in Figure 1, reviewers identify more strongly with preparers from the local office (mean of 3.35) versus preparers from an international office (mean of 2.10). Similarly, related to Link 3, reviewers are more likely to anticipate a personal benefit with preparers that are likely to recur (mean of 6.83) vs. preparers who are unlikely to recur (mean of 5.89). Panel B also indicates significant positive associations $(\mathrm{p}<0.05)$ between OFFICE and IDENTITY, as well as RECUR and BENEFIT. ${ }^{9}$

\section{[INSERT TABLE 1 ABOUT HERE]}

We also include frequency distributions, means, and standard deviations for INTENTION, PROFDEV, and ERRORDETECTION in Figure 2 Panels A-C to illustrate the variation in these outcome variables. Of particular note is the variation we observe for the participant-reported variable INTENTION and the related, but independently evaluated, variable PROFDEV. While the majority of reviewers intended for the preparer to benefit from the review process, there were some reviewers who were less inclined (Figure 2 Panel A). As such, despite all participants receiving the exact same set of preparer workpapers, $P R O F D E V$ varies substantially in our sample (Figure 2 Panel B). In addition, while several reviewers were assessed as offering a very low level of PROFDEV (e.g., rated 0, 1, or 2), no reviewers were assessed as providing a very high level of PROFDEV (e.g., rated 8, 9, or 10). Last, in Panel C we also observe significant variation in the number of preparer errors identified by reviewers (ERRORDETECTION). In

\footnotetext{
${ }^{9}$ Although we provide correlations between all of our measured and independent variables, we do not expect each of the measured variables to vary directly with the independent variables. Hayes [2013], along with others (Bollen [1989], Rucker, Preacher, Tormala, and Petty [2011]) indicate that mediation analysis does not require a direct association between independent variables and dependent variables and, in fact, suggest that this precondition is misguided.
} 
sum, Figure 2 Panels A-C illustrate the substantial variation in reviewer intentions and review quality (both professional development and error detection) captured in our study.

\section{[INSERT FIGURE 2 ABOUT HERE]}

\subsection{TEST OF THE HYPOTHESES}

Consistent with Hayes’s [2013] recommendations on mediation analyses, and similar to analyses performed in Glover, Prawitt, and Wood [2008] and Brasel, Doxey, Grenier, and Reffett [2016], we conduct a path analysis in SPSS Amos Version 24 using maximum likelihood estimation structural equation modeling to enable simultaneous testing of our hypotheses. Figure 3 illustrates the path analysis model along with the significance of the specific links predicted by the hypotheses. Overall, the model fits the data well. The chi-square is insignificant $\left(\mathrm{X}^{2}=13.17\right.$, $\mathrm{p}=0.51$ ), the RMSEA is below 0.05 (RMSEA=0.00), both the goodness of fit and adjusted goodness of fit statistics are greater than 0.90 (GFI=0.97, AGFI=0.95), and the CFI is greater than 0.95 (CFI=1.00) (Byrne [2001], Byrne [2010]). ${ }^{10}$

\section{[INSERT FIGURE 3 ABOUT HERE]}

We examine the significance of each of the links hypothesized to formally test our specific hypotheses. H1 predicts that reviewers will identify more with a preparer from the reviewers' local office (versus an international office) and, in turn, exhibit greater intentions for the preparer to benefit from the review process. Thus, this hypothesis predicts that Links 1 and 2 will be positive and significant. As shown in Figure 3, the link from OFFICE to IDENTITY

\footnotetext{
10 The standardized indirect effects of both OFFICE and RECUR are significant on PROFDEV ( $\mathrm{p}=0.05$ and 0.01 , respectively) and ERRORDETECTION ( $\mathrm{p}=0.048$ and $<0.01$, respectively).
} 
(Link 1) is positive and significant (standardized regression weight ( $\mathrm{SRW}=0.46, \mathrm{p}<0.01$ ), as is the link from IDENTITY to INTENTION (Link 2) (SRW=0.18, p=0.02). H1 is supported. ${ }^{11}$

$\mathrm{H} 2$ posits that the reviewer will anticipate deriving a personal benefit from coaching the preparer when the preparer is likely (vs. unlikely) to recur on the engagement and, in turn, exhibit greater intentions for the preparer to benefit from the review process. As shown in Figure 3, the links from RECUR to BENEFIT (Link 3) and BENEFIT to INTENTION (Link 4) are both positive and significant ( $S R W=0.21, \mathrm{p}=0.01$; $\mathrm{SRW}=0.44, \mathrm{p}<0.01$, respectively). $\mathrm{H} 2$ is supported. ${ }^{12}$

H3 predicts that reviewers will provide review comments that focus more on professionally developing the preparer when the reviewer intends for the preparer to benefit from the review process. As shown in Figure 3, Link 5 from INTENTION to PROFDEV is positive and significant (SRW=0.33, $\mathrm{p}<0.01)$, supporting H3.

Finally, H4 is stated in the null: the extent to which reviewers provide review comments that professionally develop the preparer will not influence the reviewers' detection of preparer errors. This null hypothesis posits that Link 6 will not be significant. However, contrary to this hypothesis, we observe that the link from PROFDEV to ERRORDETECTION is positive and highly significant (SRW=0.35, $\mathrm{p}<0.01$ ). In other words, as reviewers focused their review

\footnotetext{
${ }^{11}$ Because office location could alter the extent to which reviewers anticipate face-to-face interactions, we also measured and tested whether the likelihood that participants expected to interact with the preparer face-to-face mediated the relation between OFFICE and INTENTION. We find that, although OFFICE significantly influences the anticipation of face-to-face interaction with Sam on the Madison engagement $(t=10.97, p<0.01)$ and other engagements $(\mathrm{t}=4.67, \mathrm{p}<0.01)$, such anticipation does not mediate the relation between OFFICE and INTENTION ( $>00.10)$. We also tested whether the OFFICE manipulation may have, in the minds of our participants, manipulated the competence of the preparer (e.g., PCAOB [2014]; [2016]; [2017a]). We observe that reviewers' perceptions of the preparer's competence do not differ by OFFICE $(\mathrm{t}=-0.36, \mathrm{p}>0.10)$ and does not mediate the relation between OFFICE and INTENTION ( $>0.10$ ). As such, we conclude that identification with the preparer, and not anticipation of face-to-face encounters or perceptions of preparer competence, is driving our $\mathrm{H} 1$ result.

${ }^{12} \mathrm{Of}$ all of the factors in the model, BENEFIT has the largest indirect effect on both PROFDEV $(\mathrm{p}<0.01)$ and ERRORDETECTION $(\mathrm{p}<0.01)$, highlighting the substantial role self-interest plays in determining review quality.
} 
comments more on developing the preparer, the extent to which the reviewers detected errors in the preparer's substantive testing increased significantly. ${ }^{13}$ This result is positive in the sense that one objective of the review process (development of preparers) seems to reinforce the other (error detection). However, it also leads to a question as to whether this synergy results in a trade-off, whereby more effective reviewers are less efficient. We examine this trade-off below.

\subsection{SUPPLEMENTAL ANALYSES}

4.4.1 Review Efficiency. In order to evaluate the impact of focusing on professional development vis-à-vis audit efficiency, we replace ERRORDETECTION with TIME (measured as the number of minutes the reviewer took to complete their review) in our model. This replacement had some impact on the model fit, but the fit statistics still indicate the model fits the data fairly well $\left(\mathrm{X}^{2}=19.18, \mathrm{p}=0.16\right.$; RMSEA=0.06; GFI=0.96; AGFI=0.92). In addition, we observe that the link between PROFDEV and TIME is positive and significant (SRW=0.22 $\mathrm{p}=0.01$ ). The more reviewers focused on professionally developing the preparer, the more time they took to complete their review. ${ }^{14}$ Although a focus on professional development does come with the cost of decreased efficiency, the dual benefits of increased error detection and the coaching offered to preparers seem to outweigh this cost.

4.4.2. Moderation. We also examine the possibility that RECUR might moderate the effect of OFFICE. For example, if international preparers are less likely to be developed professionally, could signaling recurrence to their reviewer mitigate this effect? We find,

\footnotetext{
13 To ensure that our model specified the directional impact appropriately, we also tested whether ERRORDETECTION impacts PROFDEV. When we allowed these variables to influence one another rather than constrain the relation to PROFDEV influencing ERRORDETECTION, we find that the influence of ERRORDETECTION on PROFDEV is insignificant (SRW=-0.40, p=0.27), whereas the impact of PROFDEV on ERRORDETECTION is still significant (SRW=0.66, $\mathrm{p}=0.01$ ). This provides some evidence that our directional interpretation is appropriate. Similarly, reversing the order of causality between PROFDEV and INTENTION results in an insignificant path (SRW<-0.01, $\mathrm{p}=0.99)$.

${ }^{14}$ In a similar analysis, we also find $P R O F D E V$ to be positively associated with the overall word count of the review.
} 
however, that the interaction is not significant $(\mathrm{t}=0.01, \mathrm{p}=0.99)$. Rather than just moderating the effect of office location, RECUR boosts PROFDEV and ERRORDETECTION for both local and international preparers. If a reviewer believes a preparer will recur, review quality is higher regardless of their office affiliation. Thus, our results suggest that early signaling of a desire to recur is a controllable factor that all preparers can use to obtain coaching that enhances their professional development.

4.4.3 Experience and Review Quality. Our measures of review quality, PROFDEV and ERRORDETECTION, could also be considered measures of review performance. Libby and Luft [1993] posit that experience, along with mental ability and knowledge, determine performance in accounting settings. Libby and Tan [1994] examine the relation between auditor experience and performance and suggest that both general and specific forms of experience impact performance. In our experiment, we measured participants’ general audit experience (GENEXP, measured in months), their general experience with reviewing workpapers (REVEXP, measured on a scale ranging from 0 (No Experience) to 10 (Extensive Experience)), and whether they had specific experience reviewing workpapers documenting the search for unrecorded liabilities (SPECEXP, coded as yes $=1$, no $=0$ ). To examine the impact of these experience measures on review quality, we performed two ordinal regressions with PROFDEV and ERRORDETECTION as the dependent variables. ${ }^{15}$

Surprisingly, in an untabulated analysis we do not observe that any of the three experience measures are significantly associated with $P R O F D E V$ ( $\mathrm{p}>0.10$ for all). While our

\footnotetext{
${ }^{15}$ While we observe positive correlations between the three measures of experience (ranging from 0.43 to 0.57 ), all correlations are less than the 0.80 level for which it is suggested that multicollinearity be examined (Gujarati [2003]). In addition, variance inflation factors for the three measures range from 1.37 to 1.64, all falling well below acceptable thresholds (Belsley, Kuh, and Welsch [1980], Neter, Kutner, Nachtsheim, and Wasserman [1996], Kennedy [2008]).
} 
tests of hypotheses suggest that situational factors such as RECUR and OFFICE can impact PROFDEV, it is interesting that PROFDEV may not be a behavior that that is simply enhanced with more practice or experience. With respect to ERRORDETECTION, in Table 2 we observe significant positive associations with both $\operatorname{GENEXP}(\mathrm{p}=0.01)$ and $\operatorname{REVEXP}(\mathrm{p}=0.05)$. Thus, more experienced reviewers appear to detect more errors. This result should inform firms about the possible consequences to review quality associated with “experienced hires” performing reviews. ${ }^{16}$

\section{[INSERT TABLE 2 ABOUT HERE]}

Last, contrary to what one would expect, in Table 2 we observe that SPECEXP is negatively associated with ERRORDETECTION ( $\mathrm{p}=0.04)$. It is possible that reviewers with more experience directly related to our task were perhaps over confident and, in turn, less apt to detect errors (e.g., Pincus [1991]). Examining why more familiarity with reviewing an audit test could impair review quality, and if such effects persist to other audit tests of varying complexity levels, represents a fruitful area for future research.

\section{Conclusions}

Audit workpaper review is a quality control mechanism with two key dimensions: detecting preparer errors in the short-term and professionally developing staff in the long-term. As audit teams become more global, new contextual factors are introduced into the audit environment that may influence a supervisor’s review quality. In this study, we investigate how the preparer's office location (local vs. international) and the likelihood of preparer recurrence

\footnotetext{
${ }^{16}$ By "experienced hires" we refer to professionals/CPAs with substantial accounting experience with business entities that are hired by audit firms. These professionals have little or no prior audit experience, but based on their experience levels begin as a second year associate or an audit senior. As such, as was the case in our sample, some audit seniors have less than the two years of audit experience one would expect of a senior. Our results indicate that these less experienced seniors, while equally adept at coaching, may be less equipped to detect preparer errors in audit tests that they themselves may have never performed (i.e., they may have skipped the preparer phase for a given audit area).
} 
affect the reviewer's propensity to focus on the professional development of the preparer. We also examine if an emphasis on professional development either enhances or detracts from the other objective of the review process: error detection.

Overall, our results indicate that contextual factors associated with a preparer, which may or may not be within the preparer's control, can significantly impact the level of professional development offered by reviewers. Also, as reviewers focus more on professional development, we observe that their ability to detect errors in the workpapers increases. Our findings point to one important negative effect of engagements that involve international auditors: a possible reduction in review quality. On the other hand, regardless of office affiliation, preparers who indicate their desire to recur are likely to receive better coaching. Thus, when possible, preparers can actively influence the quality of coaching they receive by initiating discussions with their reviewers early on about recurring on the next year's engagement. Audit firms can also work to ensure that "recurrence" is more likely to occur through human resource practices that plan and maintain engagement team continuity and reduce turnover amongst preparers.

Our findings point to potentially fruitful areas for future research. First, we find that identification with preparers is an important factor to reviewers investing time to professionally develop them. Therefore, investigating ways to encourage identification between team members working in various global locations are potential directions for future research in the increasingly global environment of audits. Second, SIT suggests that lower identification may also occur with auditors working in the same country, but in different office locations. Further research is needed to examine whether identification differs across domestic office locations. Third, the work of the preparer is kept constant in our study. Future studies can examine how recurring or office location affect the work of preparers. For example, are recurring or local office preparers more 
apt to stylize their audit documentation to impress or persuade reviewers that they are likely to interact with in the future? If so, do reviewers anticipate and adapt to such stylization attempts to maintain an acceptable level of review quality (e.g., Tan and Trotman [2003])? Last, while we find recurrence is beneficial to preparer professional development, future research may examine whether there is a "right" amount of recurrence, as professional development may also benefit from preparers experiencing a diverse set of reviewers. 


\section{APPENDIX}

Part A: Each Coder's Reflection on What Professional Development/Coaching Is

Instructions: Think about the audit workpaper review process. Please describe your thoughts on how review comments and/or edits to workpapers can be used to enhance the professional development of audit staff? Feel free to provide examples.

\section{Coder 1:}

The review process is important with regards to ensuring audit quality but is also important for audit staff development. In my experience, review comments that help develop auditors seem to take one of three general forms - instructional, explanatory, or thoughtprovoking. Instructional review comments can help audit staff by identifying issues within the workpaper, such as gaps in the evidence collected, inconsistencies in audit documentation, or potential audit issues that need to be investigated further, and providing guidance and instructions on how the staff should handle those issues. These types of review notes help teach auditors that there are things they should have noticed and/or considered, and help them learn what steps should be taken to address those issues.

Explanatory review comments can help audit staff by making the appropriate adjustments within the workpaper and then explaining in the review note what changes were made and why. These types of review notes can achieve the goal of pointing out developmental areas to audit staff and demonstrating a good way to address those issues without the time consuming back and forth. Thought-provoking review notes may point out potential issues but challenge the staff to think through and suggest ways to address the issue. These type of review notes can be very time consuming for audit staff to deal with but they not only demonstrate and point out issues, but also teach audit staff to think through what's going on and how to address it.

\section{Coder 2:}

Note: Prior to pursuing a $\mathrm{PhD}$, I was an audit senior manager at a Big 4 accounting firm. My thoughts are given from this perspective.

The workpaper review process has three main purposes, listed in order of importance: 1) verify that the audit work is performed and documented according to appropriate auditing standards and firm audit methodology, 2) assist in professional development of less-experienced auditors, and 3) evaluate performance. The first purpose is already addressed in the audit literature and is not the subject of the question above. The second and third workpaper review purposes are addressed below.

The supervising auditors can use the audit workpaper review process to assist in the professional development of less-experienced auditors through instruction on proper audit methodology and proper writing technique. When instructing on proper audit methodology, workpaper review comments should help the audit staff consider:

1. Whether all the appropriate procedures are performed.

2. Whether the auditor has thought about the management assertions and related risks and designed and performed procedures to address those risks. 
3. Whether the appropriate procedures are selected to address the management assertion and related risks (e.g. analytical procedures, substantive test of details, appropriate sample sizes, etc.).

When instructing on proper writing technique, workpaper review comments should help the audit staff consider:

1. Whether the purpose, procedures, and conclusion are all linked to the appropriate management assertions and related risks.

2. Whether the auditor uses clear and concise language to communicate the auditor judgment employed, the procedures performed, and reasons for the conclusions reached during the audit.

3. The use of proper spelling and grammar. (unfortunately a college degree does not guarantee this)

Through the audit manager or partner providing comments and the auditor addressing these comments and correcting their procedures and workpapers, the auditor gains experience regarding proper audit technique and communication, which may be used in future audits.

Finally, the workpaper review process can be a tool to evaluate auditor performance. Through reviewing workpapers, the reviewer can potentially assess whether the auditor is able to think through the problem, design appropriate audit procedures to address it, and communicate what has been done, judgment involved, and conclusions reached. Auditors that copy audit procedures from the prior year without considering whether these are still appropriate for the audit client's current situation are not demonstrating proper judgment when selecting audit procedures, and this may also be an indication of performance problems when performing these audit procedures or even ghost-ticking. Sloppy workpapers (e.g. poor grammar, spelling, workpaper structure) and the continuation of such after proper coaching can be a sign of an ineffective auditor. I have seen a correlation between poor documentation and less effective audit procedures, and this is often a subject of discussion during performance evaluation meetings.

Part B: Examples of Professional Development Provided to Coders Prior to Coding:

Professional development involves improving employees job performance and enhancing their capabilities by providing feedback, encouraging critical thinking, and stimulating future learning (Heslin et al. [2006], Gregory and Levy [2010]). With this in mind, we provided the coders with the following examples of how the reviewer's (participant's) comments may assist in Sam's professional development along these dimensions.

- Instructing Sam regarding gaps in the evidence collected, inconsistent or incomplete audit documentation, potential audit issues that need to be investigated further.

- Explaining to Sam changes that were made to the workpaper by the reviewer (participant) and why; and/or

- Highlighting potential issues and challenging Sam to think through and attempt to address the issues.

- Asking Sam questions to stimulate his thinking and learning. 
Part C: Examples of Review Comments Rated High and Low for Professional Development (PROFDEV)

\section{Participant Review Comments Rated High for Professional Development}

Example 1: Please add more details in the purpose, explaining why we selected certain period for TW and why particular threshold was used. Does the misstatement identify trigger controls? What is the impact? Any control deficiency assessment performed? How did we get comfort over C\&A of IPE provided for selection?

Example 2: How did we check the C\&A of the account payable population and the C\&A of the disbursement population? How does this tie to the invoice differences? Get contract, looks like this will be performed in 2015, should all of 405,000 be included in 2014? Have these been rec'd by the client? Be more elaborate here. What is going on in the situation. Don't follow.

Example 3: Have we inspected our accrual workpapers to see if the identified amounts were accrued for? If not in the AP Aging, it is possible they were accrued for and may not actually be improperly excluded. We need to verify this since we currently are proposing an audit adjustment. Capital Scaffolding - If the invoice was received in December, the invoice needs to be processed into AP, so the full amount of the invoice should be recorded in AP at 12/31/14. It is possible that the Company appropriately recorded half the expense in 2014 and the other half to a prepaid asset. Please inspect our prepaid workpapers to see how the Company treated the expense side of the journal entry, but the Company's treatment of AP is appropriate. Capital Tile selection - Goods received on 1/2/15. Is policy FOB shipping or destination? If terms were FOB shipping, this could belong in AP at 12/31/14. Please investigate and update documentation accordingly. Triple Lay Bricks - when were goods received? Terms are FOB destination - could impact our assessment. Let's discuss.

\section{Participant Review Comments Rated Low for Professional Development}

Example 1: Please vouch documentation more carefully. I found at least 3 mistakes (see below). Let me know when you redo it.

Example 2: On this w/p, there should be amount of Accounts Payable Listing 2014. There is no information of Account Temps on the PBC of Account Payable Listing 12/11/2014.

Example 3: For Capital Scaffolding, please adjust the 2014 FS Recognition to say "Note 1" as it is unclear now whether it was properly included/excluded. Keep documentation consistent as you move forward (included vs excluded). Please ref to wp that the AP listing was agreed to the trial balance. 


\section{REFERENCES}

Abdolmohammadi, M. J. “A comprehensive taxonomy of audit task structure, professional rank and decision aids for behavioral research.” Behavioral Research in Accounting 11 (1999): 51-92.

Agoglia, C.P., R. C. Hatfield, and J. F. Brazel. "The effects of audit review format on review team judgments.” Auditing: A Journal of Practice and Theory 28 (10) (2009): 95-11.

Agoglia, C.P., J. F. Brazel, R. C. Hatfield, and S. B. Jackson. ”How do audit workpaper reviewers cope with the conflicting pressures of detecting misstatements and balancing client workloads?” Auditing: A Journal of Practice and Theory 29 (2) (2010): 27-43.

Agoglia, C. P., T. Kida, and D. M. Hanno. "The effects of alternative justification memos on the judgments of audit reviewees and reviewers.” Journal of Accounting Research 41 (1) (2003): 33-46.

Ajzen, I. “Theory of planned behavior.” Organizational Behavior and Decision Processes 50 (2) (1991): 179-211.

Ajzen, I. "Perceived behavioral control, self-efficacy, locus of control and the theory of planned behavior.” Journal of Applied Social Psychology 32 (4) (2002): 665-683.

Andiola, L. M., and J. C. Bedard. "Delivering the tough message: Moderators of subordinate auditors' reactions to feedback.” Accounting, Organizations and Society (2018) (forthcoming).

Andiola, L. M., J. C. Bedard, and J. Kremin. “On-the-job coaching quality and turnover intentions in a multiple supervisor context: Does one bad apple spoil the barrel?” Unpublished Paper, Virginia Commonwealth University, Bentley University, and Portland State University, 2018a.

Andiola, L. M., D. H. Downey, B. C. Spilker, and T. J. Noga. “An examination of the interactive effect of feedback source and sign in the offshoring environment: A social identity perspective.” Behavioral Research in Accounting (2018b) (forthcoming).

Andiola, L. M., J. C. Bedard, and K. D. Westermann. "It's not my fault! Insights into subordinate auditors' attributions and emotions following audit review." Auditing: A Journal of Practice $\&$ Theory (2018c) (forthcoming).

Aron, A., E. N. Aron, and D. Smollan. "Inclusion of other in the self scale and the structure of interpersonal closeness.” Journal of Personality and Social Psychology 63 (4) (1992): 596612.

Asare, S. K., C. M. Haynes, and J. G. Jenkins. "The effects of client and preparer risk factors on workpaper review effectiveness.” Behavioral Research in Accounting 19 (1) (2007): 1-17.

Bauer, T. "The effects of client identity strength and professional identity salience on auditor judgments.” The Accounting Review 90 (1) (2015): 95-114.

BDO International Limited (BDO). "Invitation to Comment: Enhancing Audit Quality in the Public Interest.” 2016. Available at: https://www.ifac.org/publications-resources/invitationcomment-enhancing-audit-quality-public-interest.

Belsley, D. A., E. Kuh, and R. E. Welsch. Regression Diagnostics: Identifying Influential Data and Sources of Collinearity. New York, NY: John Wiley, 1980.

Bollen, K. A. Structural equations with latent variables. New York, NY: John Wiley and Sons, 1989.

Bonache, J., H. Langinier, and C. Zarraga-Oberty. "Antecedents and effects of host country nationals negative stereotyping of corporate expatriates. A social identity analysis.” Human Resource Management Review 26 (1) (2016): 59-68. 
Brasel, K. M. M. Doxey, J. H. Grenier, and A, Reffett. "Risk disclosure preceding negative outcomes: The effects of reporting critical audit matters on judgments of auditor liability." The Accounting Review 91 (5) (2016): 1345-1362.

Brazel, J. F., C. P. Agoglia, and R. C. Hatfield. "Electronic versus face-to-face review: The effects of alternative review on auditors’ performance.” The Accounting Review 79 (4) (2004): 949-966.

Byrne, D., C. Gouaux, W. Griffitt, J. Lamberth, N. Murakawa, M. Prasad, A. Prasad, and M. Ramirez III. "The ubiquitous relationship: Attitude similarity and attraction: A cross-cultural study.” Human Relations 24 (3) (1971): 201-207.

Byrne, B.M. Structural Equation Modeling with AMOS. Mahwah, NJ: Lawrence Erlbaum Associates, 2001.

Byrne, B. M. Structural Equation Modeling with AMOS: Basic Concepts, Applications, and Programming. $2^{\text {nd }}$ ed., edited by Harlow, L. New York, NY: Routledge, 2010.

Carson, E. "Industry specialization by global audit firm networks.” The Accounting Review 84 (2) (2009): 355-382.

Carson, E. “Globalization of Auditing.” In the Routledge Companion to Auditing, edited by D. Hay, W. R. Knechel, and M. Wilekens, 23-32. New York, NY: Routledge, 2014.

Christensen, B. and N. Newton. "How does audit team staffing affect audit outcomes? Archival evidence from U.S. audits.” Unpublished paper, University of Missouri and University of Oklahoma, 2017.

Church, P. H. “Assimilation of new hires in public accounting.” Current Issues in Auditing 8 (2) (2014): A25-A34.

Cramton, C. D., and P. J. Hinds. "Subgroup dynamics in internationally distributed teams: Ethnocentrism or cross-national learning?” Research in Organizational Behavior 26 (2005): 231-263.

Covaleski, M., M. W. Dirsmith, J. B. Heian, and S. Sajay. "The calculated and the avowed: Techniques of discipline and struggles over identity in Big Six.” Administrative Science Quarterly 43 (2) (1998): 293-327.

Dovidio, J. F. "Helping behavior and altruism: An empirical and conceptual overview." Advances in Experimental Social Psychology 17 (1984): 361-427.

Dovidio, J. F., K. Kawakami, C. Johnson, B. Johnson, and A. Howard. "On the nature of prejudice: Automatic and controlled processes.” Journal of Experimental Social Psychology 33 (5) (1997): 510-540.

Dovidio, J. F. J. A. Piliavin, S. Gaertner, D. A. Schroeder, and R. D. Clark. "The arousal: Costreward model and the process of intervention: A review of evidence." In Prosocial Behavior: Review of Personality and Social Psychology, edited by M. Clark, 86-118. Newbury Park, CA: Sage, 1991.

Downey. D. H. “An exploration of offshoring in audit practice and the potential consequences of associated work "re-design” on auditor performance." Auditing: A Journal of Practice \& Theory 37 (2) (2018): 197-224.

Downey, D. H., and J. C. Bedard. "Coordination and communication challenges in global group audits.” Auditing: A Journal of Practice \& Theory (2018) (forthcoming).

Durocher, S., M. Bujaki, and F. Brouard. “Attracting millennials: Legitimacy management and bottom-up socialization processes within accounting firms.” Critical Perspectives on Accounting 39 (1) (2016): 1-24. 
Fargher, N. L., D. Mayorga, and K. T. Trotman. "A field-based analysis of audit workpaper review.” Auditing: A Journal of Practice \& Theory 24 (2) (2005): 85-110.

Ferguson, L. "Statement on the proposed amendments relating to the supervision of audits involving other auditors and proposed auditing standard - dividing responsibility for the audit with another accounting firm." Speech delivered at the PCAOB open board meeting, April 12, 2016.

Fishbein, M., and I. Ajzen. "Predicting and changing behavior: the reasoned action approach.” New York, NY: Psychology Press, 2010.

Fogarty, T. J. "Organizational socialization in accounting firms: A theoretical framework and agenda for future research.” Accounting, Organizations and Society 17 (2) (1992): 129-149.

Frank, M. L., and V. B. Hoffman. "How audit reviewers respond to an audit preparer's affective bias: The ironic rebound effect.” The Accounting Review 90 (2) (2015): 559-557.

Gibbins, M., and K. T. Trotman. “Audit review: Managers’ interpersonal expectations and conduct of the review." Contemporary Accounting Research 19 (3) (2002): 411-444.

Gimbar, C., J. G. Jenkins, G. Saucedo, and N. Wright. "Shifting styles: Do audit documentation reviewers tailor feedback on audit engagements to preparer performance levels?” Working paper, DePaul University, Virginia Tech, Seattle University, and James Madison University, 2017.

Glover, S. M., D. F. Prawitt, and D. A. Wood. "Internal audit sourcing arrangement and the external auditor's reliance decision.” Contemporary Accounting Research 25 (1) (2008): 193213.

Grerogy, J. B. and P. E. Levy. "Employee coaching relationships: enhancing construct clarity and measurement.” Coaching: An International Journal of Theory, Research and Practice 3 (2) (2010): 109-123.

Gujarati, D. “Basic Econometrics.” 4 $4^{\text {th }}$ ed. New York: McGraw-Hill, 2003.

Halbesleben, J. R. B., and M. Westman. "Getting to the 'COR': Understanding the role of resources in conservation of resources theory.” Journal of Management 40 (5) (2014): 13341364.

Harris, S. "Statement on the proposed amendments relating to the supervision of audits involving other auditors and proposed auditing standard - dividing responsibility for the audit with another accounting firm.” Speech delivered at the PCAOB open board meeting, April 12, 2016.

Hayes, A. F. "Introduction to mediation, moderation, and conditional process analysis.” New York, NY: The Guildford Press, 2013.

Herda, D. N., and J. J. Lavelle. "The auditor-audit firm relationship and its effect on burnout and turnover intention.” Accounting Horizons 26 (4) (2012): 707-723.

Heslin, P. A., D. O. N. Vandewalle, and G. P. Latham. "Keen to help? Managers' implicit person theories and their subsequent employee coaching.” Personnel Psychology 59 (4) (2006): 871902.

Hobfoll, S. E. “Conservation of resources: A new attempt at conceptualizing stress.” American Psychologist 44 (3) (1989): 513-524.

International Auditing and Assurance Standards Board (IAASB). “The Clarified International Standards on Auditing - Findings from the Post-Implementation Review.” New York, N.Y.: IAASB, 2013a.

International Auditing and Assurance Standards Board (IAASB). "Shaping New Solutions to Global Issues: IAASB Annual Report.” New York, N.Y.: IAASB, 2013b. 
Jenkins, J. G., B. Ater, C. Gimbar, G. Saucedo, and N Wright. “Audit roles and the review process: Workpaper preparers' and reviewers’ differing perspectives.” Working Paper, Virginia Polytechnic Institute and State University, The University of Texas Rio Grande Valley, DePaul University, Seattle University, and James Madison University, 2018.

Kennedy, P. “A Guide to Econometrics.” 6th edition. Cambridge, MA: MIT Press, 2008.

Kim S., D. M. Mayorga, and N. Harding. "Can I interrupt you? Understanding and minimizing the negative effects of brief interruptions on audit judgment quality." International Journal of Auditing 21 (2017): 198-211.

Kornberger, M., L. Justesen., and J. Mouritsen. "When you make manager, we put a big mountain in front of you: An ethnography of managers in a Big 4 accounting firm.” Accounting, Organizations and Society 36 (8) (2011): 514-533.

KPMG. "Elevating professional judgment in auditing and accounting: The KPMG professional judgment framework.” Montvale, N.J.: KPMG LLP, 2011.

Lambert, T. and C. Agoglia. "Closing the loop: Review process factors affecting audit stff follow-through.” Journal of Accounting Research 49 (5) (2011): 1275-1306.

Lau, D. C., and J. K. Murnighan. "Demographic diversity and faultlines: The compositional dynamics of organizational groups.” The Academy of Management Review 23 (2) (1998): 325-340.

Lauck, J., and S. Bhattacharjee. "The effects of supervisor preferences and group engagement oversight on component auditor skepticism in a group audit engagement.” Working paper, Louisiana Tech University and Virginia Polytechnic Institute and State University, 2017. Available at: https://papers.ssrn.com/sol3/papers.cfm?abstract_id=2690421.

Levina, N., and E. Vaast. "Innovating or doing as told? Status differences and overlapping boundaries in offshore collaboration.” MIS quarterly 32 (2) (2008): 307-332.

Libby, R., and J. Luft. "Determinants of judgment performance in accounting settings: Ability, knowledge, motivation, and environment.” Accounting Organizations and Society 18 (5) (1993): 425-450.

Libby, R., and H. Tan. "Modeling the determinants of audit expertise.” Accounting Organizations and Society 19 (8) (1994): 701-716.

Mullis, C. and R. Hatfield. "The effects of multitasking on auditors'judgment quality." Contemporary Accounting Research 35 (1) (2018): 314-333.

National Association of State Boards of Accountancy (NASBA). Mutual recognition agreements. 2018. Available at: https://nasba.org/international/mra/.

Neter, J., M. H. Kutner, C. J. Nachtsheim, and W. Wasserman. “Applied Linear Statistical Models.” $4^{\text {th }}$ edition. New York, NY: McGraw-Hill, 1996.

Oriel, F. H., D. Mobbs, D. Evans, L. Hiscox, L. Navrady, and T. Dalgleish. "What we say and what we do: The relationship between real and hypothetical moral choices.” Cognition 123 (3) (2012): 434-441.

Peecher, M. E., Piercey, M. D., Rich, J. S., and Tubbs, R. M. “The effects of a supervisor’s active intervention in subordinates' judgments, directional goals, and perceived technical knowledge advantage on audit team judgments.” The Accounting Review 85 (5) (2010): 1763-1786.

Pincus, K. V. “Audit Judgment Confidence.” Behavioral Research in Accounting 3 (1991): 3965. 
Public Company Accounting Oversight Board (PCAOB). PCAOB Release No. 105-2014-024: Order instituting disciplinary proceedings, making findings, and imposing sanctions in the Matter of Akiyo Yoshida, CPA, Respondent. Washington, D.C.: PCAOB, 2014.

Public Company Accounting Oversight Board (PCAOB). PCAOB Release No. 2016-002: Proposed amendments relating to the supervision of audits involving other auditors and proposed auditing standard - dividing responsibility for the audit with another accounting firm. Washington, D.C.: PCAOB, 2016.

Public Company Accounting Oversight Board (PCAOB). PCAOB Sanctions Former Pricewaterhouse Coopers Brazil Partner for Audit Failures Washington, D.C.: PCAOB, 2017a.

Public Company Accounting Oversight Board (PCAOB). PCAOB Solicits Additional Public Comment on Proposed New Requirements for Lead Auditor's Use of Other Auditors Washington, D.C.: PCAOB, 2017b.

Pychyl, T. A. “Closing the Intention-Action Gap.” Psychology Today (March 11, 2009). Available at: https://www.psychologytoday.com/blog/dont-delay/200903/closing-theintention-action-gap.

Rucker, D. D., K. J. Preacher, Z. L. Tormala, and R. E. Petty. "Mediation analysis in social psychology: Current practice and new recommendations." Personality and Social Psychology Compass 5/6 (2011): 359-371.

Sheeran, P. "Intention-behavior relations: A conceptual and empirical review." European Review of Social Psychology 12 (1) (2002): 1-36.

Sunderland, D. and G. M. Trompeter. "Multinational group audits: Problems faced in practice and opportunities for research.” Auditing: A Journal of Practice \& Theory 36 (3) (2017): 159-183.

Tajfel, H. "Human groups and social categories: Studies in social psychology.” Cambridge, United Kingdom: Cambridge University Press, 1981.

Tan, H., and K. T. Trotman. "Reviewers responses to anticipated stylization attempts by preparers of audit workpapers." The Accounting Review 78 (2) (2003): 581-604.

Tombu, M., and P. Jolicœur. "Virtually no evidence for virtually perfect time-sharing.” Journal of Experimental Psychology: Human Perception and Performance 30 (2004): 795-810.

Tropp, L. R. and S. C. Wright. "Ingroup identification as the inclusion of ingroup in the self." Personality and Social Psychology Bulletin 27 (5) (2001): 585-600.

Trotman, K. T., T. D. Bauer, and K. A. Humphreys. "Group judgment and decision making in auditing: Past and future.” Accounting, Organizations and Society 47 (2015): 56-72.

Vera-Munoz, S. C., J. L. Ho, and C. W. Chow. "Enhancing knowledge sharing in public accounting firms.” Accounting Horizons 20 (2) (2006): 133-155.

Westermann, K. "Learning the "craft of auditing": Applications of the cognitive apprenticeship framework.” Doctoral dissertation, Bentley University, 2011.

Westermann, K. D., J. C. Bedard, and C. E. Earley. "Learning the craft of auditing: A dynamic view of auditors on the job learning." Contemporary Accounting Research 32 (3) (2015): 864-896.

Wickens, C. D. "The structure of attentional resources.” In Attention and Performance VIII, edited by R. S. Nickerson, 239-257. Hillsdale, NJ: Erlbaum Associates, 1980.

Wilks, T. J. "Predecisional distortion of evidence as a consequence of real-time audit review." The Accounting Review 77 (1) (2002): 51-71. 
Williamson, G. M., and M. S. Clark. "Impact of desired relationship type on affective reactions to choosing and being required to help.” Personality and Social Psychology Bulletin 18 (1) (1992): 10-18. 
FIGURE 1

Theoretical Model

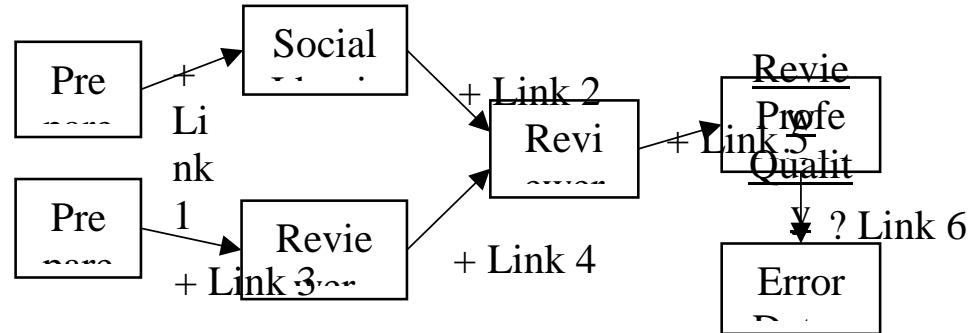

See Figure 3 for all variable definitions. 
FIGURE 2

Frequency Distributions of Reviewers' Intentions and Review Quality

Panel A: Reviewer Intends to Benefit the Preparer (INTENTION) - Frequency Distribution

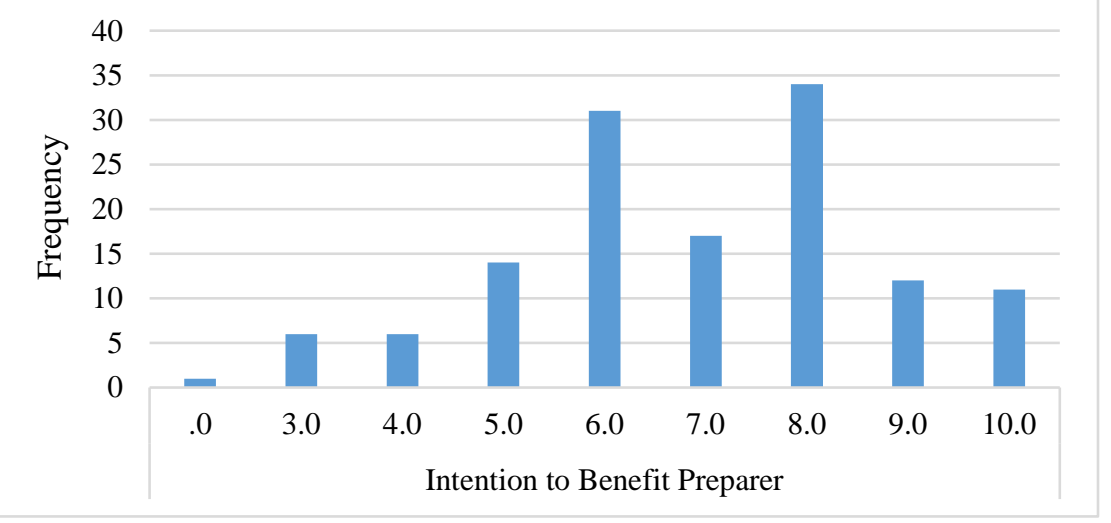

Panel B: Extent of Reviewer's Professional Development of the Preparer (PROFDEV) Frequency Distribution

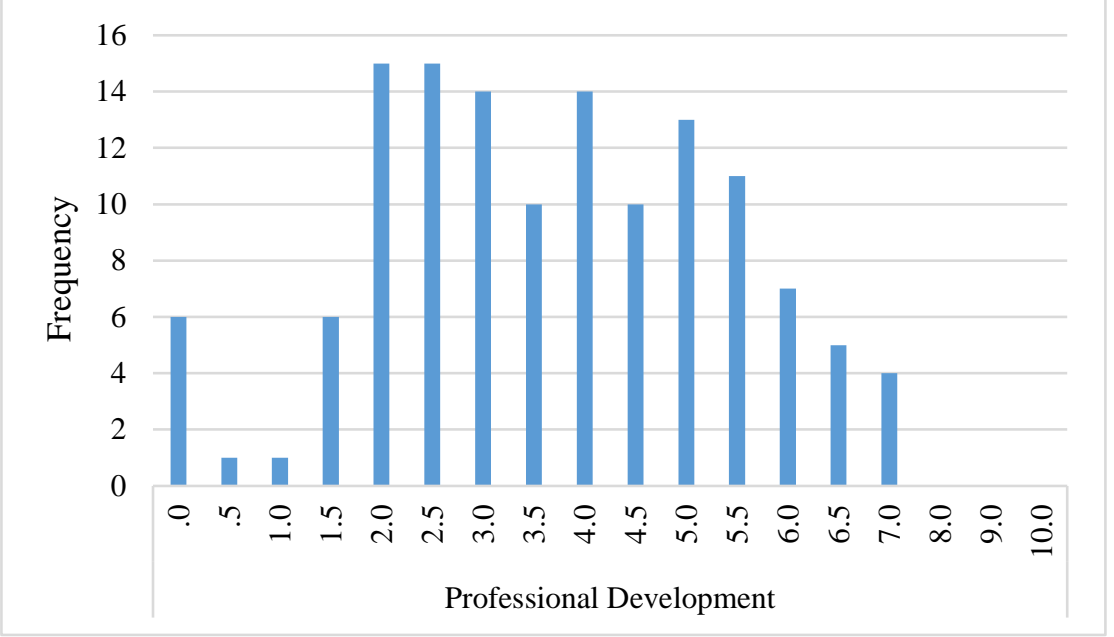

\section{Panel C: Error Detection (ERRORDETECTION) - Frequency Distribution}

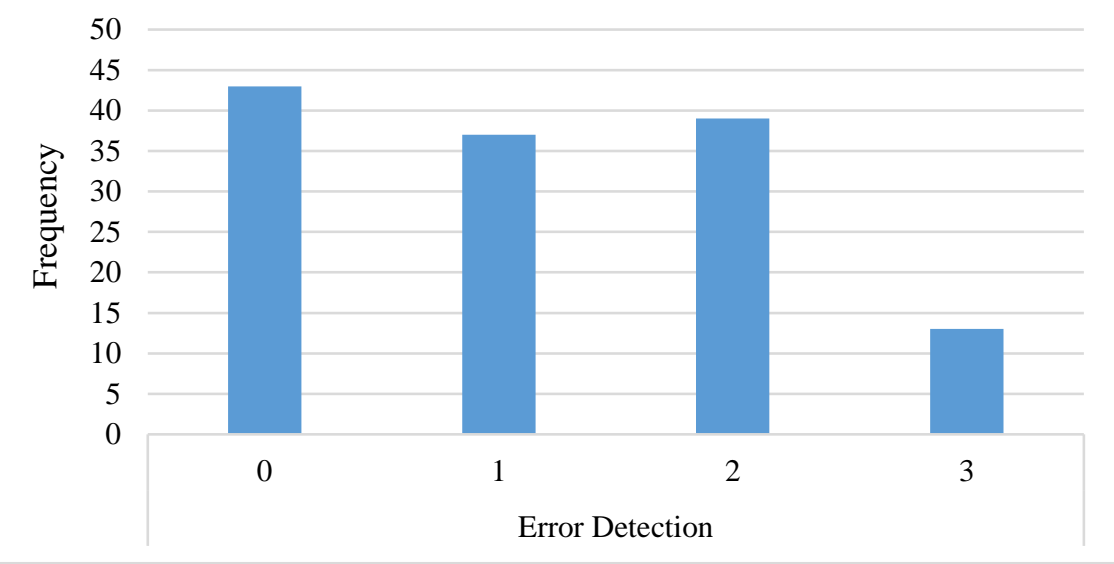


Panel A presents the frequency distribution of Intentions to Benefit the Preparer (INTENTION), the mean (SD) is 6.87 (1.88). Panel B presents the frequency distribution of the Extent of the Reviewer's Professional Development of the Preparer (PROFDEV), the mean (SD) is 3.67 (1.72). Panel C presents the frequency distribution of the Reviewer's Error Detection (ERRORDETECTION), the mean (SD) is 1.17 (1.00). See Figure 3 for all variable definitions. 
FIGURE 3

Path Analysis - Hypotheses Testing Results of Theoretical Model

\section{Path Model Fit Statistics}

$\mathrm{X}^{2}=13.17, \mathrm{p}=0.51$

RMSEA $=0.00$

$\mathrm{GFI}=0.97$

AGFI $=0.95$

$\mathrm{CFI}=1.00$

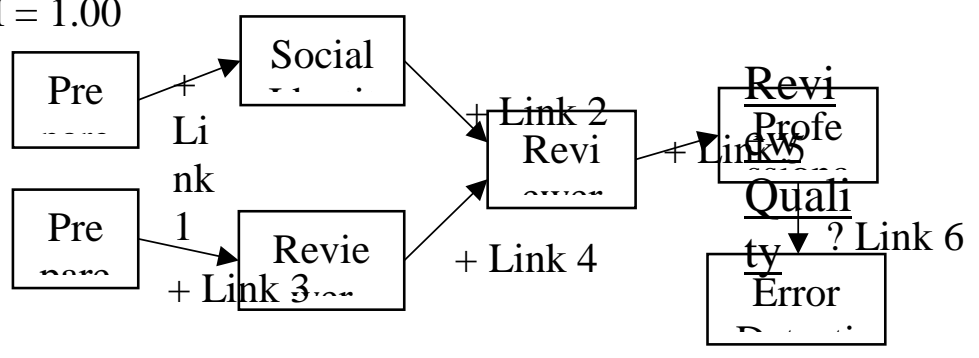




\section{FIGURE 3 continued \\ Path Analysis - Hypotheses Testing Results of Theoretical Model}

We conduct the path analysis in SPSS Amos Version 24 using maximum likelihood estimation structural equation modeling to enable simultaneous testing of our hypotheses. We present the path model with standardized regression weights (SRW). Variables are defined below:

OFFICE was manipulated as local (the preparer was an experienced staff member working out of your local office) or international (the preparer was an experienced staff member working out of another international office of the firm).

RECUR was manipulated by noting that the preparer was either likely or unlikely to recur on the Madison, Inc. engagement.

IDENTITY was measured as the extent to which reviewers identified with the preparer. Participants were provided with six Venn diagrams describing levels of overlap with their preparer and were asked to, "Select the number that most closely matches the professional closeness of your relationship with [the preparer].” Responses were given on a scale (which corresponded to the six Venn diagrams) ranging from 1 (Very Distant) to 7 (Very Close).

BENEFIT was measured by asking participants, "How much would you (either on Madison or another engagement) benefit in the future from the coaching you provided Sam in the search for unrecorded liabilities testing?” Responses to the questions were measured on a scale ranging from 0 (No Benefit) to 10 (Extensive Benefit).

INTENTION was measured by asking participants, "How much would Sam benefit from the review process for the search for unrecorded liabilities testing?” Responses to the questions were measured on a scale ranging from 0 (No Benefit) to 10 (Extensive Benefit).

PROFDEV was assessed by two accounting doctoral students with significant audit experience. For each participant, the students were told to do the following: "After reading the review comments for each participant, please rate the amount of effort the reviewer (participant) put into [the preparer's] professional development, as evidenced by the review comments." The students responded on a scale ranging from 1 (Very Low Effort) and 10 (Very High Effort). PROFDEV is the average of the two ratings supplied by the two students.

ERRORDETECTION was measured as the number of seeded errors ( 0 to 3 ) identified by the participant in their review notes. 
TABLE 1

Descriptives

Panel A: Descriptive Statistics

\begin{tabular}{|c|c|c|c|c|c|c|c|c|c|c|c|}
\hline \multirow[b]{3}{*}{ OFFICE } & \multirow[b]{2}{*}{$n$} & \multicolumn{2}{|c|}{ IDENTITY } & \multicolumn{2}{|c|}{ BENEFIT } & \multicolumn{2}{|c|}{ INTENTION } & \multicolumn{2}{|c|}{ PROFDEV } & \multicolumn{2}{|c|}{$\begin{array}{c}\text { ERROR } \\
\text { DETECTION }\end{array}$} \\
\hline & & Mean & $S D$ & Mean & $S D$ & Mean & $S D$ & Mean & $S D$ & Mean & $S D$ \\
\hline & & & & & & & & & & & \\
\hline Local & 65 & 3.35 & 1.31 & 6.26 & 2.20 & 6.94 & 2.08 & 3.63 & 1.69 & 1.11 & 0.99 \\
\hline International & 67 & 2.10 & 1.10 & 6.46 & 2.32 & 6.81 & 1.69 & 3.70 & 1.75 & 1.22 & 1.01 \\
\hline RECUR & & & & & & & & & & & \\
\hline Likely & 66 & 2.86 & 1.37 & 6.83 & 1.87 & 7.05 & 1.62 & 3.70 & 1.64 & 1.11 & 0.96 \\
\hline Unlikely & 66 & 2.56 & 1.33 & 5.89 & 2.51 & 6.70 & 2.11 & 3.63 & 1.80 & 1.23 & 1.03 \\
\hline
\end{tabular}

Panel B: Correlations

\begin{tabular}{|c|c|c|c|c|c|c|}
\hline & 2 & 3 & 4 & 5 & 6 & 7 \\
\hline 1. OFFICE & 0.02 & 0.46 & 0.05 & 0.10 & -0.02 & -0.06 \\
\hline 2. RECUR & 1 & 0.11 & 0.21 & 0.10 & 0.02 & -0.06 \\
\hline 3. IDENTITY & & 1 & -0.05 & 0.24 & 0.07 & -0.03 \\
\hline 4. BENEFIT & & & 1 & 0.46 & 0.16 & 0.20 \\
\hline 5. INTENTION & & & & 1 & 0.33 & 0.22 \\
\hline 6. PROFDEV & & & & & 1 & 0.35 \\
\hline 7. ERRORDETECTION & & & & & & 1 \\
\hline
\end{tabular}

Panel A presents the means and standard deviations (SDs) for the outcome variables for each independent variable, OFFICE and RECUR. Panel B presents the correlation matrix. The bolded correlations indicate significance at $\mathrm{p}<0.05$, two-tailed. See Figure 3 for all variable definitions. 
TABLE 2

Experience and Review Quality

Dependent Variable: ERRORDETECTION

Estimated

\begin{tabular}{lccc} 
Independent Variable & Coefficient & Wald-statistic & $\mathrm{p}$ \\
\hline GENEXP & 0.03 & 7.92 & 0.01 \\
REVEXP & 0.18 & 3.85 & 0.05 \\
SPECEXP & -0.88 & 4.47 & 0.04 \\
Model chi-square statistic = 15.75 & & 0.01 \\
Pseudo $\mathrm{R}^{2}=.12$ & & \\
\hline ERRORDETECTION was measured as the number of seeded errors (0 to 3) identified by the participant in their \\
review notes. GENEXP measured participants' general audit experience in months. REVEXP measured participants' \\
general experience with reviewing workpapers on a scale ranging from 0 (No Experience) to 10 (Extensive \\
Experience). SPECEXP measured whether participants had specific experience reviewing workpapers documenting \\
the search for unrecorded liabilities (coded as yes = 1, no = 0).
\end{tabular}

